\title{
Biopsies of the Internal Mammary Sentinel Lymph Nodes in Breast Cancer
}

\begin{abstract}
Keywords: Breast cancer; Internal mammary lymph node; Prognosis; Treatments

\section{Abstract}

Background: The aim of the present study was to report internal mammary sentinel lymph node (IM SLN) biopsy results and to review and discuss their impact on treatment and prognosis.

Patients and methods: We retrospectively reviewed the data from 107 patients who underwent a biopsy of IM nodes after the IM SLN was visualised (in 16 patients, only the IM SLN was visualised) by preoperative lymphoscintigraphy after peritumoural and intra-mammary injections of $99 \mathrm{mTc}$-human serum albumin nanocolloids.

Results: In 9 out of 107 patients, exploration of the IM node chain was not successful. Seven $(8.6 \%)$ of the 82 patients with axillary (Ax) and IM SLN visualisation had a pathologically positive $(\mathrm{pN}+)$ IM SLN while, $3(20 \%)$ of the 16 patients, in whom only the IM SLN could be visualised, had a $\mathrm{pN}+\mathrm{IM}$ SLN. Three patients with $\mathrm{pN}+\mathrm{IM}$ SLN status were administered chemotherapy and five patients underwent irradiation of the parasternal chain. However, the pN- IM SLN status of 16 patients argued against such irradiation. The $\mathrm{pN}+$ IM SLN status also changed the PTNM stage in six patients, the Nottingham Prognostic Index score in five patients, and the percentages of relapse risk and/o of cancer-related death (based on "Adjuvant Online") in six patients.

Conclusions: An IM SLN biopsy can be safely performed and is recommended when lymphoscintigraphy reveals IM chain drainage. The $\mathrm{pN}+$ IM SLN status can affect treatment decisions.
\end{abstract}

\section{Introduction}

The introduction of the sentinel lymph node (SLN) concept and its biopsy have deeply changed the management of many cancers $[1,2]$. The SLN is defined as the first LN to which cancer cell are most likely to spread from a primary tumour; in cT1-T2 breast cancer patients, the axillary (Ax) SLN biopsy is now considered the standard of care for staging clinically node-negative patients [3]. The AxLNs are the main LN basin of the breast, hence the main determinant of the patient's LN status. However, the second lymphatic drainage basin of the tumour-bearing breast is represented by the internal mammary lymph nodes (IM LNs) and is often overlooked (if not ignored). Evaluation (imaging or operative) is not done routinely during the staging process in most breasts because the clinical importance of metastases in the IM LNs and their selective lymphadenectomy has been debated since the introduction of this technique. The aim of the present paper was to report the results from IMSLN biopsies and to review and discuss their impact on treatment and prognosis.

\section{Patients and Methods}

We retrospectively reviewed the data of 107 women with invasive breast cancer who underwent a biopsy of the IMSLN between January 2000 and May 2009. The basic criteria for the biopsy were: (1) visualisation of the IMSLN in the lymphoscintigraphic examination of the Ax SLN and (2) the IM SLN could be biopsied through the same

\section{Journal of} Surgery
Mirela Roman ${ }^{1 *}$, Clarence Karler ${ }^{2}$, Jean-Marie Nogaret ${ }^{1}$, Pierre Bourgeois ${ }^{3}$ and Catherine Philippson $^{4}$

'Department of Mammo-Pelvic Surgery, Jules Bordet Institute, Brussels, Belgium

2Department of Anesthesia, Iris Sud, Brussels, Belgium

${ }^{3}$ Department of Nuclear Medicine, Jules Bordet Institute, Brussels, Belgium

${ }^{4}$ Department of Radiation Oncology, Jules Bordet Institute, Brussels, Belgium

*Address for Correspondence

Mirela Roman, Department of Mammo-pelvic Surgery, Jules Bordet Institute, 121, Bd. de Waterloo, B-1000, Brussels, Belgium, Tel: +32 2541 31 64; Fax: +32 254131 31; E-mail: mirela-mariana.roman@bordet.be

Submission: 21 April, 2016

Accepted: 13 May, 2016

Published: 18 May, 2016

Copyright: () 2016 Roman M et al. This is an open access article distributed under the Creative Commons Attribution License, which permits unrestricted use, distribution, and reproduction in any medium, provided the original work is properly cited.

incision as for the lumpectomy to avoid a second incision. Women with neo-adjuvant chemotherapy were excluded. A concomitant or delayed Ax LN dissection was performed, either when the Ax SLN was positive or when the tumour size was bigger than $20 \mathrm{~mm}$ in the frozen section.

\section{Lymphoscintigraphy}

Patients received four peritumoural and intra-mammary injections $(0.2 \mathrm{~mL} \times 2.0 \mathrm{mica})$ of ${ }^{99 \mathrm{~m}} \mathrm{Tc}$-labelled human serum albumin (HSA) nanosizedcolloids (Nanocoll) the day before the operation. Mammary and Ax mapping scintigraphic scans were taken 3 to 6 $\mathrm{h}$ thereafter. When only the IMSLN was visualised after the intramammary and peritumoural injections of the radio-colloids, patients were injected intradermally with $0.4 \mathrm{ml}$ of the same colloids to show the Ax SLN.

\section{Surgical detection and resection of the SLN}

During surgery, a gamma probe was used to guide the surgeon and the SLN was removed. With regard to the AxLNs, the surgeons removed all LNs with a count rate higher than 10 percent of the activity found in the most active LN. Blue dye was never used during an operation.

\section{Pathology}

Pathological examination of all SLNs consisted of hematoxylineosin staining. If this was negative, additional serial sectioning was performed for immunohistochemical staining (CAM 5.2) [4].

Adjuvant treatments and irradiation of the internal mammary nodes

Chemotherapy was systematically given to patients with macrometastases in the AxLNs and/or with a Grade III tumour [5,6] (Ki67 and the presence of micrometastases in the Ax nodes were also taken into account). The parasternal LN chain was systematically 
Citation: Roman M, Karler C, Nogaret JM, Bourgeois P, Philippson C. Biopsies of the Internal Mammary Sentinel Lymph Nodes in Breast Cancer. J Surgery. 2016;4(1): 7.

ISSN: $2332-4139$

Table 1: Clinicopathologic characteristic of patients undergoing IM SLN dissection.

\begin{tabular}{|c|c|c|c|c|}
\hline & & Negative IMSLN & Positive IM SLN & $p$ value \\
\hline & & $N=88$ & $N=10$ & \\
\hline \multirow[t]{3}{*}{ Age (years) } & $<50$ & $11(12.5 \%)$ & $1(10 \%)$ & 0.242 \\
\hline & $51-60$ & $22(25 \%)$ & $5(50 \%)$ & \\
\hline & $>61$ & $55(62.5 \%)$ & $4(40 \%)$ & \\
\hline Tumour & Internal & $64(72.73 \%)$ & $7(70 \%)$ & 0.983 \\
\hline \multirow[t]{2}{*}{ localisation } & Medial & $8(9.09 \%)$ & $1(10 \%)$ & \\
\hline & External & $16(18.18 \%)$ & $2(20 \%)$ & \\
\hline \multirow[t]{3}{*}{ type } & Lobular & $14(17.5 \%)$ & $2(20 \%)$ & \\
\hline & Mixed & $3(3.4 \%)$ & $0(0 \%)$ & \\
\hline & Other & $5(5.6 \%)$ & $0(0 \%)$ & \\
\hline Tumour size & $1 \mathrm{a}$ & $7(7.95 \%)$ & $1(10 \%)$ & 0.508 \\
\hline \multirow[t]{3}{*}{$(\mathrm{mm})$} & $1 b$ & $13(14.77 \%)$ & $3(30 \%)$ & \\
\hline & 1c & $60(68.18 \%)$ & $6(60 \%)$ & \\
\hline & 2 & $8(9.09 \%)$ & $0(0 \%)$ & \\
\hline Histologic & 1 & $21(23.86 \%)$ & $2(20 \%)$ & 0.648 \\
\hline grade & II & $44(50 \%)$ & $4(40 \%)$ & \\
\hline \multirow[t]{3}{*}{ Ki 67} & $0-10$ & $49(55.68 \%)$ & $5(50 \%)$ & 0.603 \\
\hline & $>10$ & $36(40.91 \%)$ & $4(40 \%)$ & \\
\hline & ND & $3(4.91 \%)$ & $1(10 \%)$ & \\
\hline Axillary & NO & $76(86.36 \%)$ & $5(50 \%)$ & 0.014 \\
\hline involvement & $\mathrm{N}+$ & $12(13.64 \%)$ & $5(50 \%)$ & \\
\hline
\end{tabular}

*Only ductal and lobular histotypes were compared. ND: Not Defined; IM SLN: Internal Mammary

Sentinel Lymph Node.

irradiated when metastasis was found in the Ax nodes and/or when the tumour was located in the medial or internal quadrant and had a pathological size larger than $20 \mathrm{~mm}$ [7].

\section{Evaluation of $\mathrm{pN}$ and $\mathrm{pTNM}$ staging}

The influence of the IM SLN pathological results on the $\mathrm{pN}$ and pTNM staging was also analysed based on the AJCC Cancer Staging Manual, Seventh Edition [8].

Evaluation of the patients' prognosis based on the Nottingham Prognostic Index

The first method to estimate the impact of the IM SLN status on the patients' prognosis was the Nottingham Prognostic Index (NPI) [9], which was calculated for all patients with and without taking into account the $\mathrm{pN}$ status of the IM SLN. The NPI was calculated with following formula: NPI $=[0.2 \times S]+N+G$, where $S$ is the size of the index lesion in $\mathrm{cm}$; $\mathrm{N}$ is the number ( $\mathrm{n}$ ) of LNs involved (if $\mathrm{n}=0, \mathrm{~N}$ $=1$; if $\mathrm{n}=1-3, \mathrm{~N}=2$; if $\mathrm{n}>3, \mathrm{~N}=3$ ); and $\mathrm{G}$ is the grade of tumour (Grade I =1, Grade II =2, Grade III =3). Based on the value obtained, each patient was assigned to one of three prognostic groups: good (NPI $\leq 3.4)$, moderate $(3.4<\mathrm{NPI} \leq 5.4)$, or poor $(>5.4)$. In addition, the change related to the addition of the IM SLN biopsy was evaluated.

\section{Evaluation of the patients' prognosis based on "Adjuvant Online" data}

To estimate the risk of relapse and cancer-related death in patients with a pN+ IM SLN more precisely than using their pTN staging and/ or their NPI, their respective risks were calculated using version 8 of 
Citation: Roman M, Karler C, Nogaret JM, Bourgeois P, Philippson C. Biopsies of the Internal Mammary Sentinel Lymph Nodes in Breast Cancer. J Surgery. 2016;4(1): 7.

ISSN: $2332-4139$

Table 2: Comparison of characteristics of patients who had "only" visualisation of IM SLN versus those who had IM and Ax SLN visualisation ( $N=98$ ).

\begin{tabular}{|c|c|c|c|c|}
\hline & & Only IM SLN & Ax and IM SLN & $P$ value \\
\hline & & $N=16$ & $N=82$ & \\
\hline \multirow[t]{3}{*}{ Age (years) } & $<50$ & $0(0 \%)$ & $12(14.63 \%)$ & 0.263 \\
\hline & $51-60$ & $5(31.25 \%)$ & $22(26.83 \%)$ & \\
\hline & $>61$ & $11(68.75)$ & $48(58.54 \%)$ & \\
\hline Tumour & Internal & $11(68.75 \%)$ & $60(73.17 \%)$ & 0.316 \\
\hline \multirow[t]{2}{*}{ localisation } & Medial & $3(18.75 \%)$ & $6(7.32 \%)$ & \\
\hline & External & $2(12.50 \%)$ & $16(19.51 \%)$ & \\
\hline Histologic & Ductal & $12(75 \%)$ & $62(75.61 \%)$ & 0.672 \\
\hline \multirow[t]{3}{*}{ type } & Lobular & $2(12.50 \%)$ & $14(17.07 \%)$ & \\
\hline & Mixed & $0(0 \%)$ & $3(3.66 \%)$ & \\
\hline & Others & $2(12.5 \%)$ & $5(6.1 \%)$ & \\
\hline Tumour & $1 \mathrm{a}$ & $1(6.25 \%)$ & $7(8.54 \%)$ & 0.007 \\
\hline \multirow[t]{3}{*}{ size $(m m)$} & $1 b$ & $7(43.75 \%)$ & $9(10.98 \%)$ & \\
\hline & 1c & $6(37.50 \%)$ & $60(73.17 \%)$ & \\
\hline & 2 & $2(12.5 \%)$ & $6(7.32 \%)$ & \\
\hline Histologic & I & $5(31.25 \%)$ & $18(21.95 \%)$ & 0.724 \\
\hline grade & II & 7 (43.75\%) & $41(50 \%)$ & \\
\hline \multirow[t]{3}{*}{ KI 67} & $0-10$ & $10(62.50 \%)$ & $44(53.66 \%)$ & 0.657 \\
\hline & $>10$ & $5(31.25 \%)$ & 35 (42.68\%) & \\
\hline & ND & $1(6.25 \%)$ & $3(3.66 \%)$ & \\
\hline Axillary & No & $14(87.50 \%)$ & 67 (81.71\%) & 0.842 \\
\hline involvement & $\mathrm{N}+$ & $2(12.50 \%)$ & 15 (18.29\%) & \\
\hline Internal & No & $13(81.25 \%)$ & $75(91.46 \%)$ & 0.433 \\
\hline involvement & $\mathrm{N}+$ & $3(18.75 \%)$ & $7(8.54 \%)$ & \\
\hline
\end{tabular}

IM SLN: Internal Mammary Sentinel Lymph Node; Ax SLN: Axillary Sentinel Lymph Node

"Adjuvant Online" [10].

\section{Statistical analysis}

The R Software, version 3.0.1, was used for statistical analysis. Groups were compared using the Chi-Square test or the Fisher's exact test. P values $\leq 0.05$ were considered statistically significant [11].

\section{Results}

The present data are retrospective. The first biopsy of the IM SLN was performed in 01/2000 and the last one in $05 / 2009$. In between these temporal limits, a total of 2228 lymphoscintigraphic investigations were performed to visualise the SLN (58.9\% of tumours were located in the external quadrants, $16.7 \%$ in the median quadrants, and $24.5 \%$ in the internal ones; more precisely, $15.2 \%$ were in the upper inner quadrant). In 39 patients (1.75\%), the lymphoscintigraphy showed only the IM SLN; while, in 1562 patients (70.1\%) it showed only the Ax SLN. In 533 patients (23.9\%), the Ax and IM SLNs were visualised. The lymphoscintigraphy failed to demonstrate any LN in 94 patients (4.2\%).

Only 107 of the 572 patients with IM drainage on 
Citation: Roman M, Karler C, Nogaret JM, Bourgeois P, Philippson C. Biopsies of the Internal Mammary Sentinel Lymph Nodes in Breast Cancer. J Surgery. 2016;4(1): 7.

ISSN: 2332-4139

Table 3: Stage migration in patients with IM lymph node metastases $(n=10)$.

\begin{tabular}{|c|c|c|c|c|c|c|c|}
\hline \multirow[b]{2}{*}{ Patient Number } & \multirow[b]{2}{*}{ pT (mm) } & \multirow[b]{2}{*}{ pNAx } & \multirow[b]{2}{*}{ pN IM } & \multicolumn{2}{|c|}{ pN staging base } & \multicolumn{2}{|c|}{ pTNM stage base } \\
\hline & & & & Only Ax & With IM & Only Ax & With IM \\
\hline 1 & 10 & 0 & 1 micro & pNO & $\mathrm{pN} 1 \mathrm{~b}$ & la & Ila \\
\hline 2 & 15 & 4 macro & 2 macro & $\mathrm{pN} 2 \mathrm{a}$ & $\mathrm{pN} 3 \mathrm{~b}$ & IIla & IIIc \\
\hline 3 & 11 & 0 & 1 micro & pNO & $\mathrm{pN} 1 \mathrm{~b}$ & la & Ila \\
\hline 4 & 17 & 1 macro & 2 macro & pN1a & $\mathrm{pN} 1 \mathrm{c}$ & Ila & Ila \\
\hline 5 & 5 & 0 & 1 micro & pNO & $\mathrm{pN} 1 \mathrm{~b}$ & la & Ila \\
\hline 6 & 8 & 0 & 2 macro & pNO & $\mathrm{pN} 1 \mathrm{~b}$ & la & Ila \\
\hline 7 & 13 & 1 macro & 2 macro & $\mathrm{pN} 1 \mathrm{a}$ & $\mathrm{pN} 1 \mathrm{c}$ & Ila & Ila \\
\hline 8 & 15 & 1 micro & 1 micro & pN1a & $\mathrm{pN} 1 \mathrm{c}$ & Ila & Ila \\
\hline 10 & 9 & 1 macro & 4 macro & pN1a & pN3b & Ila & IIIc \\
\hline
\end{tabular}

pTNM: Pathological examination of the size of the primary tumour "T", of the regional lymph node "N",

and the presence of distant metastasis "M"; Ax: Axillary; IM: Internal Mammary

Table 4: There lapse risk and/or cancer related deaths calculated on the basis of "Adjuvant Online" and Fong's NPI $(N=10)$.

\begin{tabular}{|c|c|c|c|c|c|}
\hline \multicolumn{6}{|c|}{ Adjuvant Online with Hormonal therapy and/or Chemotherapy } \\
\hline \multicolumn{2}{|c|}{$\%$ of relapse } & \multicolumn{2}{|c|}{$\%$ of cancer related deaths } & \multicolumn{2}{|c|}{ Fong's NPI 10 year survival } \\
\hline 21.7 & 44.4 & 7.9 & 32.6 & 84 & 77 \\
\hline 10.2 & 18.4 & 6.3 & 15.1 & 84 & 77 \\
\hline 23.3 & 23.3 & 11.3 & 11.3 & 77 & 77 \\
\hline 7.2 & 15.3 & 0.6 & 7 & 89 & 77 \\
\hline 5.1 & 9.2 & 0.5 & 4.5 & 89 & 84 \\
\hline 8.1 & 8.1 & 4.3 & 4.3 & 84 & 84 \\
\hline 11.9 & 18.4 & 5.5 & 13.8 & 89 & 77 \\
\hline 11.8 & 19.8 & 7.5 & 15.3 & 77 & 77 \\
\hline
\end{tabular}

IM: Internal Mammary; NPI: Nottingham Prognostic Index

lymphoscintigraphy had an IM SLN biopsy. The reasons for this were the lack of experience of the operating surgeon, the IM SLN located beyond one rib and/or the sternum, and the site of the lumpectomy was a distance from the IM SLN (implying an additional incision). In 9 of the 107 patients, these approaches were either unsuccessful or non-contributive (no nodal material at the pathological exam). Of interest, 7 of these 9 failures were observed during the first 2 years ( 4 of 18 during 2000 and 3 of 17 during 2001). One of the 98 patients with a successful IM SLN biopsy had a pneumothorax.

Pathologically positive IM nodes were found in $10.2 \%$ (10 of 98) of patients. Three (20\%) of the 16 patients with visualisation "only" of the IM SLN and 7 (8.6\%) of the 82 patients with visualisation of the IM and Ax SLNs presented with metastases of the IM SLN. In $5(29.4 \%)$ of 17 patients with Ax metastases, the IM nodes were involved. Histopathology examination showed macrometastases in five patients and micrometastases in five patients.

The characteristics of all 98 patients are shown in Table 1. The presence of Ax metastases was associated with the IM involvement ( $\mathrm{p}$ $=0.014$ ). There was a correlation between patients with "only" IMSLN visualisation and the size of the tumour $(\mathrm{p}=0.007)$ (Table 2). Of the 10 patients with a $\mathrm{pN}+\mathrm{IMSLN}, 7$ had a tumour in the upper inner quadrant. In the group with "only" IMSLN visualisation ( $\mathrm{n}=16), 2$ of the 3 patients with a $\mathrm{pN}+\mathrm{IMSLN}$ had a tumour in the upper inner quadrant; whereas, 5 of the 7 patients from the group with IM and Ax SLNs had a pN+ IMSLN and tumour in the upper inner quadrant. A $\mathrm{pN}$ upstaging occurred in all ten (10.2\%) patients with a pN+ IM SLN according to the $7^{\text {th }}$ edition of the TNM in breast cancer [8], and a pTNM stage migration was seen in seven patients (Table 3 ).

Five patients with a $\mathrm{pN}+\mathrm{IM}$ SLN were treated with radiotherapy to the IM chain. Sixteen of the patients who planned to receive such 
Citation: Roman M, Karler C, Nogaret JM, Bourgeois P, Philippson C. Biopsies of the Internal Mammary Sentinel Lymph Nodes in Breast Cancer. J Surgery. 2016;4(1): 7.

ISSN: $2332-4139$

Table 5: Published series concerning the visualisation, exploration, and involvement rates of IM SLNs in breast cancer patients.

\begin{tabular}{|c|c|c|c|c|c|c|c|c|c|}
\hline Authors & $\begin{array}{l}\text { No. of } \\
\text { patients }\end{array}$ & $\begin{array}{l}\text { Visualization } \\
\text { of IM SLN }\end{array}$ & $\begin{array}{l}\text { Failure } \\
\text { of biopsy }\end{array}$ & $\begin{array}{l}\text { Visualization } \\
\text { "only" IM SLN }\end{array}$ & $\begin{array}{l}\text { Patients } \\
\text { with IM+ SLN } \\
\text { visualization }\end{array}$ & $\begin{array}{l}\text { Successful } \\
\text { biopsy of } \\
\text { IM SLN }\end{array}$ & IM+ SLN & $\begin{array}{l}\text { Ax+ and } \\
\text { IM+SLN }\end{array}$ & $\begin{array}{l}\text { Ax- and } \\
\text { IM+SLN }\end{array}$ \\
\hline Heuts [18] & 1008 & $196(19.6 \%)$ & $57(29 \%)$ & $0(0 \%)$ & 0 & 139 & $31(22.3 \%)$ & 22 & 9 \\
\hline VanderEnt[19] & 256 & $65(25.4 \%)$ & $24(37 \%)$ & $0(0 \%)$ & 0 & 41 & $11(26.8 \%)$ & 8 & 3 \\
\hline $\begin{array}{l}\text { Postma } \\
{[20]}\end{array}$ & 486 & $119(24.5 \%)$ & $21(20 \%)$ & $7(1.4-5.9 \%)$ & ND & 86 & $14(16.27 \%)$ & 7 & 7 \\
\hline Madsen [22] & 506 & $109(21.5 \%)$ & $24(22 \%)$ & $3(0.6-3 \%)$ & ND & 85 & $20(23.52 \%)$ & 16 & 4 \\
\hline Carcoforo [23] & 741 & $95(12.8 \%)$ & $7(10 \%)$ & $37(5-39 \%)$ & 6 & 65 & $10(15.38 \%)$ & 5 & 5 \\
\hline Estourgie [24] & 691 & $150(21.7 \%)$ & $20(13 \%)$ & 27 (3.9-18\%) & ND & 130 & $22(16.92 \%)$ & 13 & 9 \\
\hline Parades [25] & 383 & $55(14.3 \%)$ & $12(27 \%)$ & $2(0.5-3.6 \%)$ & 0 & 32 & $5(15.62 \%)$ & 5 & 1 \\
\hline Van Esser [28] & 2203 & $426(19.3 \%)$ & $9(2.1 \%)$ & $25(1.1-5.8 \%)$ & 9 & 16 & $4(25 \%)$ & 7 & 4 \\
\hline * & 2228 & $25.65 \%$ & $9(8.5 \%)$ & $16(1.75-6.8 \%)$ & 3 & 98 & $10(10.2 \%)$ & 5 & 5 \\
\hline
\end{tabular}

* Current study; ND: No Data; IM SLN: Internal Mammary Sentinel Lymph Node; Ax:

Axillary

irradiation because their tumour was located in the inner or central quadrant were not irradiated because their IM SLN was negative. Chemotherapy was administered (on the basis on the pathological size of the tumour, the histological grading, a Ki $67>14 \%$, and the Ax status) to 50 of the 98 patients. When the status of the IM SLN was taken into account, three additional patients were to receive chemotherapy. It is important that two of these three additional patients belonged to the group where only the IM SLN was visualised.

With regard to the prognosis, the IM SLN status modified the NPI score in five patients, with four moving from a good situation to a moderate one. The percentages of relapse risk and/or of cancerrelated deaths were calculated on the basis of "Adjuvant Online". When the results of the IM SLN biopsy were taken into account, these percentages changed in 6 of the 10 patients with a pN+ IM SLN. For these six patients, the risk of relapse increased two-fold, and the percentage of cancer-related deaths worsened dramatically (Table 4).

\section{Discussion}

The anatomy and lymphatic drainage of the Ax and IM node groups differ in many ways. While the Ax group contains an average of $16 \mathrm{LNs}$, the IM node chain contains an average of "only" 4 to 5 LNs (generally of a smaller size than the Ax nodes) but this number may range from 0 to $13[12,13]$. The lymphatic drainage patterns of the breast to the Ax LN are "regular" (involving initially the first level and thereafter the following). However, the lymph coming from the upper part of the breast flows in the IMLN of the $1^{\text {st }}$ and $2^{\text {nd }}$ intercostal space and the lymph from the lowest part of the breast reaches the IMLN in the $3^{\text {rd }}$ and $4^{\text {th }}$ intercostal space before reaching the systemic circulation [14,15]. Such differences may impact the risk of IM depositing of systemic metastatic cells, especially from tumours in the upper inner quadrants, and may explain the many observations and different impacts on the prognosis.

Different studies have shown that the depth of the tracer injection, 
the characteristics of the patients, such as age and body mass, and the size of the breast influence the visualisation rate of parasternal SLNs $[16,17]$. Our results demonstrate a correlation between the localisation of the tumour and the IM SLN visualisation, with $44.2 \%$ visualisation for tumours in the inner quadrants, $31.8 \%$ for the medial quadrants, and $18.4 \%$ for the outer ones. The percentages of IM SLN visualisation range from $12.8 \%$ to $25.65 \%$ and can be partly explained by basic differences in the investigated populations and the scintigraphic approach to image the SLN (Table 5). The visualisation failures were most often caused by insufficient uptake of the tracer, sub-costal location of the SLN, the shine-through effect, lower radioactivity counts in the area intra-operatively, and the patient's age [18-20].

Initially, removal of the IM SLN was not an easy task and some experience was needed. In our study, 107 IM SLN biopsies were attempted and these approaches were reported either unsuccessful or non-contributive in 9 cases. Of interest, 7 of these failures were observed during the first 2 years of their realisation ( 4 of 18 during 2000 and 3 of 17 during 2001). Thus, a learning curve of 2 years may be necessary and/or at least 35 procedures have to be performed by the surgical team before they are considered "ready". Tanis et al. also observed a learning phase for biopsies of IM chain nodes: their identification rate was $70 \%$ in the first 30 procedures and $84 \%$ following that [21]. We also noted one patient who had a pneumothorax. Some studies showed that the morbidity of the IM SLN procedure is low [19,22-25].

The' rate of IM SLN positivity varies with the size of the primary tumour the Ax nodal status and the number of Ax nodes involved, the presence of vascular invasion, the localisation of the tumour in the breast, and the age of the patient [12,26,27]. We found metastases in $7(10 \%)$ of 71 patients if we examined only the inner tumours and 7 $(8.75 \%)$ of 80 patients if we add the central ones.

The percentages of patients with lymphatic drainage isolated to the IM chain are highly variable, with two series giving values equal to 0 but others ranging from $0.5 \%$ to $39 \%$ of the cases (Table 5). When pre-operative lymphoscintigraphy shows exclusive lymphatic drainage to the IM chain, proper staging should include exploration of the axilla because Van Esser et al. found that four of their patients with such exclusive drainage had Ax node metastases (' 'able 5) [28]. Several papers detail the presence of isolated tumour cells as well as the micro- and/or macro-metastatic status of the IM SLN [18,20,23,28]. In the study discussed above, five patients had micrometastases and five had macrometastases. Due to the direct connection between $p N+I M$ SLNs and systemic circulation, the presence of even a micrometastatic implant may be seen as evidence of the presence of systemic circulating tumour cells and of potentially distant metastases [29]. The simple scintigraphic demonstration of lymphatic drainage towards the IM LN was significantly associated with a worse distant disease-free survival but not with loco-regional recurrence or overall survival [29]. According to Veronesi et al. the prognosis is worsened by the IM node involvement and there is "stage migration [26]. In our series, stage migration was seen in seven patients.

To the best of our knowledge, this is the first analysis of the impact of the IM SLN biopsy on the NPI and the "Adjuvant Online" approach. The NPI is derived from multivariate analysis of significant prognostic parameters of breast carcinoma. This is a validated combined parameter that is suitable for tailoring adjuvant therapy on the basis of risks and benefits. It incorporates features (size and nodal status) used to determine the classical pTNM stage of breast cancer, but also takes into account the histological grade of the tumour. The index was initially defined by the size, the nodal score, and the histological grade [30]. The highest nodal score (3) was awarded when Ax apical LN and/or IM LN were involved. This first version of the NPI stressed the prognostic power of the involvement of one IM LN. However, the to-date version of the NPI takes into account only the number of positive Ax nodes [9]. In the present analysis, a modification of the NPI was observed in five of the $10 \mathrm{pN}+$ IM SLN patients. From a "practical" patient's point of view, the theoretical 5 years survival [9] dropped in three patients from $93 \%$ to $70 \%$, and in the other two from $85 \%$ to $70 \%$. However, the changes are less "dramatic" if we take into account more recently published data by Fong et al. [31]. On the basis of these last results, the theoretical 5 years survival rate drops from 93 to 90 in two patients, from 97 to 90 in two, and from 97 to 93 in the last patient. The corresponding "drops" for the 10 years survival rate of these patients were 84 to 77 for the first two patients, 89 to 77 for the second two, and 89 to 84 for the last one. When the $\mathrm{pN}+$ status of the IM SLN is taken into account in the "Adjuvant Online" approach, these percentages change in 6 of the 10 $\mathrm{pN}+\mathrm{IM}$ SLN patients with a risk of relapse that is two times higher. The cancer-related death percentages might vary from 0.5 and $0.6 \%$ (when the $\mathrm{pN}+$ status of the IMSLN is not taken into account) to $4.5 \%$ and $7.0 \%$ (when considering this status). Of note, when comparing the 10 years survival based on "Adjuvant Online" [10] (version 8.0) with the one based on Fong's NPI [31], there are differences, but there is only a major discrepancy in 2 of the 10 patients (Table 4 ).

The impact of IMSN biopsy on changing adjuvant systemic therapy is relatively small in previous reports (Table 4). In our study, IM metastases changed adjuvant systemic therapy in only $3 \%$ of the IMSLN cases that had a successful biopsy, but in 2 (12.5\%) of the 16 patients with "only" IM SLN visualisation. Considering the high incidence of breast cancer, this limited improvement in staging and treatment may have an impact on many patients. Finally, our study reflects that the pathological positivity of the IM SLN indicates irradiation of the LNs in only $5 \%$ of the patients; whereas, pathological negativity argues against irradiation in a percentage that is three times higher (16\%). The associated irradiation of the cardiac tissues and the related morbidity were also considered.

\section{Conclusions}

The removal of IM nodes is feasible and can be safely performed. However, it requires adequate training. The pathologically positive status of the IM SLN may affect treatment planning. On the other hand, a pathologically negative status as well as the associated irradiation to the cardiac tissues and morbidity may argue against irradiation. Thus, it is recommended to biopsy the IMSLN in selected patients when lymphoscintigraphy reveals IM drainage, especially from tumours in the upper inner quadrant and when pre-operative lymphoscintigraphy shows exclusive lymphatic drainage to the IM chain. 
Citation: Roman M, Karler C, Nogaret JM, Bourgeois P, Philippson C. Biopsies of the Internal Mammary Sentinel Lymph Nodes in Breast Cancer. J Surgery. 2016;4(1): 7.

ISSN: 2332-4139

\section{References}

1. Giuliano AE, Kirgan DM, Guenther JM, Morton DL (1994) Lymphatic mapping and sentinel lymphadenectomy for breast cancer. Ann Surg 220: 391-401.

2. Morton DL, Wen DR, Wong JH, Economu JS, Cagle LA, et al. (1992) Technical details of intraoperative lymphatic mapping for early stage melanoma. Arch Surg 127: 392-399.

3. Veronesi U, Paganelli G, Galimberti V, Viale G, Zurrida S, et al. (1997) Sentinel-node biopsy to avoid axillary dissection in breast cancer with clinically negative lymph-nodes. Lancet 349: 1864-1867.

4. Blumencranz P, Whitworth PW, Deck K, Rosenberg A, Reintgen D, et al (2007) Scientific Impact Recognition Award. Sentinel node staging for breast cancer: intraoperative molecular pathology overcomes conventional histologic sampling errors. Am J Surg 194: 426-432.

5. Goldhirsch A, Glick JH, Gelber RD, Senn HJ (1998) Meeting highlights: International Consensus Panel on the Treatment Of Primary Breast Cancer J Natl Cancer Inst 90: 1601-1608.

6. Goldhirsch A, Glick JH, Gelber RD, Coates AS, Senn HJ (2001) Meeting highligts: International consensus panel on the treatment of primary breast cancer. Seventh International Conference on Adjuvant Therapy of Primary Breast Cancer. J Clin Oncol 19: 3817-3827.

7. Poortmans PM, Venselaar JL, Struikmans H, Hurkmans CW, Davis JB et al. (2001) The potential impact of treatment variations on the results of radiotherapy of the internal mammary LN chain: a quality-assurance report on the dummy run of EORTC phase III randomized trial 22922 /10925 in stage I-III breast cancer. Int J Radiat Oncol Bio Phys 49: 1399-1408.

8. Edge SB, Compton CC (2010) The American Joint Committee on Cancer: the 7th edition of the AJCC cancer staging manual and the future of TNM. Ann Surg Oncol 17: 1471-1474

9. Galea MH, Blamey RW, Elston CE, Ellis IO (1992) The Nottingham Prognostic Index in primary breast cancer. Breast Cancer Res Treat 22: 207-219.

10. Adjuvant! Online.

11. R Development Core Team (2011) R: A language and environment for statistical computing. R Foundation for Statistical Computing, Vienna, Austria

12. Caceres $E$ (1959) Incidence of metastasis in the internal mammary chain in operable cancer of the breast. Surg Gynaecol Obstet 108: 715-720.

13. Bourgeois $P$, Frühling JG (1983) Internal mammary lymphoscintigraphy: current status in the treatment of breast cancer. Crit Rev Oncol Hematol 1 : $21-47$

14. Suami H, Pan WR, Mann GB, Taylor GI (2008) The lymphatic anatomy of the breast and its implications for sentinel lymph node biopsy: a human cadaver study. Ann Surg Oncol 15: 863-871.

15. Blumgart El, Uren RF, Nielsen PM, Nash MP, Reynolds HM (2011) Predicting lymphatic drainage patterns and primary tumour location in patients with breast cancer. Breast Cancer Res Treat 130: 699-705.

16. Krynyckyi BR, Chun H, Kim HH, Eskandar Y, Kim CK, et al. (2003) Factors affecting visualization rates of internal mammary sentinel nodes during lymphoscintigraphy. J Nucl Med 44: 1387-1393.
17. Leppänen E, Leidenius M, Krogerus L, von Smitten K (2002) The effect of patient and tumour characteristics on visualization of sentinel nodes after a single intratumoural injection of Tc $99 \mathrm{~m}$ labelled human albumin colloid in breast cancer. Eur J Surg Oncol 28: 821-826.

18. Heuts EM, Van der Ent FW, von Meyenfeldt MF, Voogd AC (2009) Internal mammary lymph drainage and sentinel node biopsy in breast cancer- A study on 1008 patients. Eur J Surg Oncol 35: 252-257.

19. Van der Ent FW, Kengen RA, van der Pol HA, Povel JA, Stroeken HJ, et al. (2001) Halsted revisited: internal mammary sentinel lymph node biopsy in breast cancer. Ann Surg 234: 79-84

20. Postma EL, van Wieringen S, Hobbelink MG, Verkooijen HM, van den Bongard $\mathrm{HJ}$, et al. (2012) Sentinel lymph node biopsy of the internal mammary chain in breast cancer. Breast Cancer Res Treat 134: 735-741.

21. Tanis PJ, Nieweg OE, Valdes Olmos RA, Peterse JL, Rutgers EJ, et al. (2002) Impact of non-axillary sentinel node biopsy on staging and treatment of breast cancer patients. $\mathrm{Br} \mathrm{J}$ Cancer 87: 705-710.

22. Madsen E, Gobardhan P, Bongers V, Albregts M, Burgmans J, et al. (2007) The impact on post-surgical treatment of sentinel limph node biopsy of internal mammary lymph nodes in patients with breast cancer. Ann Surg Oncol 14: 1486-1492

23. Carcoforo P, Sortini D, Feggi L, Feo CV, Soliani G, et al. (2006) Clinical and therapeutic importance of sentinel node biopsy of the internal mammary chain in patients with breast cancer: a single-center study with long-term follow-up. Ann Surg Oncol 13: 1338-1343.

24. Estourgie SH, Tanis PJ, Nieweg OE, Valdes Olmos RA, Rutgers EJ, et al. (2003) Should the hunt for internal mammary chain sentinel node begin? An evaluation of 150 breast cancer patients. Ann Surg Oncol 10: 935-9 41.

25. Paredes P, Vidal-Sicart S, Zanon G, Pahisa J, Fernandez PL, et al. (2005) Clinical relevance of sentinel lymph nodes in the internal mammary chain in breast cancer patients. Eur J Nucl Med Mol Imaging 32: 1283-1287.

26. Veronesi U, Arnone P, Vertonesi P, Galimberti V, Luini A, et al. (2008) The value of radiotherapy on metastatic internal mammary nodes in breast cancer. Results on a large series. Ann Oncol 19: 1553-1560.

27. Sugg SL, Ferguson DJ, Posner MC, Heimann R (2000) Should internal mammary nodes be sampled in the sentinel lymph node era? Ann Surg Oncol 7: $188-192$

28. van Esser S, Madsen EV, van Dalen T, Koelemij R, van Rossum PS, et al. (2011) Axillary staging in breast cancer patients with exclusive lymphoscintigraphic drainage to the internal mammary chain. World $\mathrm{J}$ Surg 35: $159-164$

29. Kong AL, Tereffe W, Hunt KK, Yi M, Kang T, et al. (2012) Impact of interna mammary lymph node drainage identified by preoperative lymphoscintigraphy on outcomes in patients with stage I to III breast cancer. Cancer 118: 62876296.

30. Haybittle JL, Blamey RW, Elston CW, Johnson J, Doyle PJ, et al. (1982) A prognostic index in primary breast cancer. $\mathrm{Br} \mathrm{J}$ Cancer 45: 361-366.

31. Fong YF, Evans J, Brookes D, Thomas KG (2012) The Nottingham prognostic index: 5-year and 10-year survival data for all-cause survival within a screened population. Breast Cancer Res 14(Suppl 1): P19. 